\title{
Use of discrete fracture networks in 3D numerical modelling for stability analysis in open pits
}

\author{
E Montiel Geocontrol Minería, Chile \\ P Varona Geocontrol Minería, Chile \\ C Fernandez Antofagasta Minerals, Chile \\ Z Espinoza Antofagasta Minerals, Chile
}

\begin{abstract}
On some occasions, structural mapping in open pit mining presents complications that do not allow for easy data collection. This causes omissions in the consideration of discontinuities (faults, fractures, joints, etc.) whose presence can be of vital importance for the stability conditions presented by the excavation itself.

Although many academic articles have based their research on the use of discrete fracture networks (DFN) and how to estimate the joint persistence in a blocky system, projection depths of structures remain ambiguous, even with the information from surveys or drilling. Still, with the interpretation of an experimented mapper, the projection of structure depths could present limitations that would prevent the formation of failure mechanisms that may occur as the project progresses.

In order to perform analyses that solve this problem, it has been found that the use of DFNs is considered a tool that allows the incorporation and assessment of the impact of geometric variations of the different structural systems being mapped, thus giving the opportunity to estimate the characteristics of importance in the structural systems as well as their involvement at depth.

In order to present the results obtained with the use of these techniques, this article aims to demonstrate that the use of DFNs incorporated stochastically in numerical modelling at the mine scale, along with the method of elements distinctions, this could answer the questions regarding the structural condition of geology in the mine.

Through the identification of failure mechanisms, this document intends to show the results obtained in a stochastic 3D evaluation where the use of DFN allows the determination of different geometrical characteristics of the pit and their stability conditions, providing solutions in the definitions of warnings in field monitoring and the validation of the project as it develops.
\end{abstract}

Keywords: slope stability, discrete fracture networks, failure mechanism, stochastic analysis

\section{Introduction}

The open pit progress and slope stability analysis interact during all stages of a mining project. In this context, the development of stability analysis allows to assess the impact of geological variations that occur during excavation, alerting possible situations or geotechnical behaviour that could require monitoring.

The slope stability analysis criteria involves evaluations against the predicted failure modes that could affect the slope at bench, inter-ramp and overall scales (Read 2009). Once the level of stability is defined, it is compared with the acceptability criteria based on security levels and economic risks established by owners and/or regulations.

The importance of failure mechanism definition becomes the main point for stability evaluation, establishing the type of analysis that will be performed and the designer's uncertain data (slope geometry, geometric characteristics of discontinuities, etc.). 
The type of stability analysis depends on two factors: the scale of slope under consideration and the materials properties that will form the slopes (Read 2009). Considering this context, the numerical analysis at inter-ramp and overall slope scale helps to assess the failure modes by recognising the interaction between discontinuities and the rock mass.

In these circumstances, while the rock mass strength can be defined as the pit's excavation progresses, the possibilities to determine the presence and depth of geological structures (particularly those that break the continuity of tensions in the ground such as faults and joints) are limited. Mathis (2016) commented on the importance of a definition method to establish the persistence of structures. This method highlighted surface mapping as the best alternative for data collection possible.

In their research, Read (2009) recommend the use of discrete fracture network (DFN) modelling as it is an important tool to visualise and analyse the spatial distribution of faults and joints according to how they have been recognised. If the DFN is integrated into the modelling of the excavation progress, the slope failure mechanisms can be detected, particularly when the failure involves sliding along the major structures and fracturing intact blocks of rocks, even if they are behind the visual slope surface.

This is exemplified in the work undertaken by Sainsbury et al. (2016) and Weir \& Fowler (2016), in which they discuss the process of DFN validation and its model verification in detail.

In an effort to demonstrate the importance of DFNs in the recognition of failure mechanisms and structural persistence stability influence, an application example in Los Pelambres mine will be presented, where its determinations will be vital for monitoring the stability of the excavation and its potentially unstable volume, which could be considered as a risk of economic impact.

\section{$2 \quad$ Analysis approach based on discrete fracture networks}

The established practice for the analysis and design of stable slopes in open pit is detailed in Read \& Stacey (2009). These guidelines involve evaluating the critical factors that determine the potential failure mode at the bench, inter-ramp and overall scales.

Given the methodologies that the guidelines indicate for the analysis of the different slope scales, the approach proposed in this document involves the use of DFN at inter-ramp and overall scale only. The reason is that at bench scale, the failure modes are much more restricted to structural control unless the rock mass presents a deficient quality situation which would lead to the rock failing due to its low resistance. At bench scale, the stress state greatly affects the confinement, limiting the development of failure mechanism that combines the rock mass with the joints.

To carry out this approach, it will be necessary to have data of faults and master joints represented as discs, where the centroid will consider the position of data collection and the measured persistence will have the diameter of the disc. With the grouped data, a statistical analysis will be executed, allowing the separation of structures by size. This will result in a discretisation by continuity which will allow the identification of the extreme dimensions or regional faults, which should be incorporated into a deterministic model.

This approach is more useful when the project has already begun (after the basic engineering stage). It is important to note that modifications or geometric validations may be required, and that the objective of this project is to determine the failure mechanisms in their interaction between rock mass discontinuity and the volume associated with each one.

Tuckey et al. (2013) made a compelling visualisation of mixed or complex failure mechanisms. In his work, he defines the interaction of five possible zones of different resistance that can act in the development of some instability at an inter-ramp or global scale (Figure 1). 


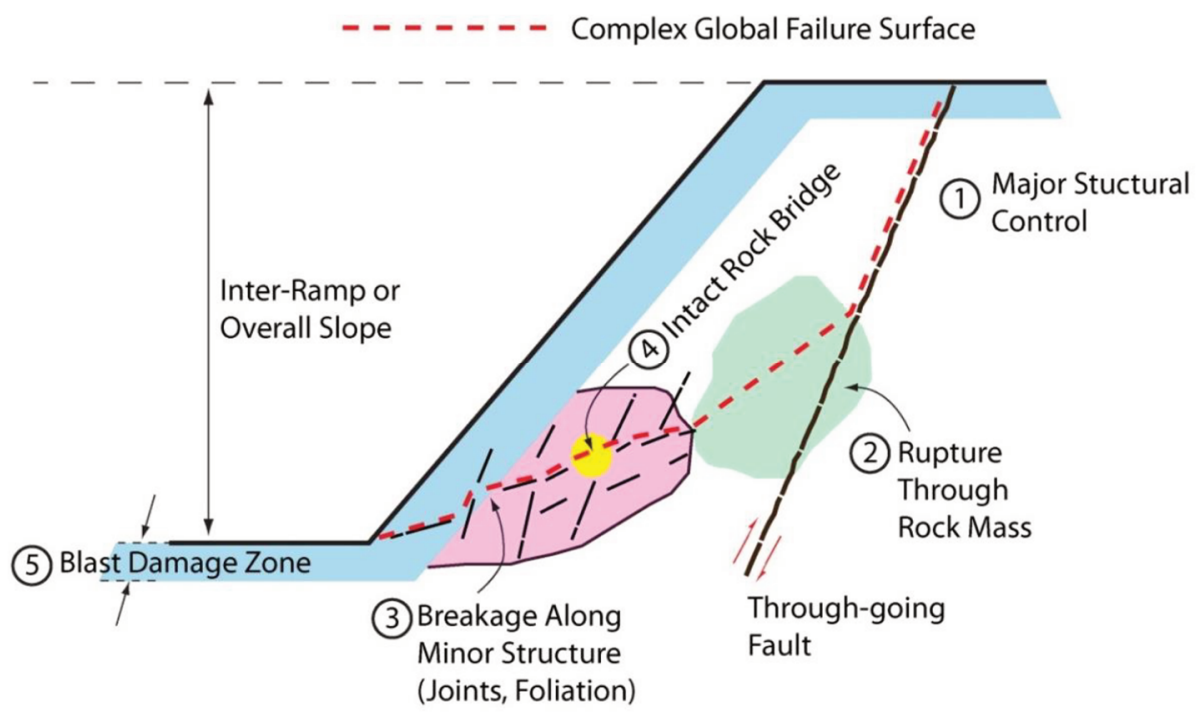

Figure 1 Conceptual illustration of a large-scale, complex slope rupture occurring through several structural domains with different shear strength properties (Tuckey et al. 2013)

Finally, the analysis will be carried out using 3D numerical models. The evaluation in this report was carried out with a distinct element method software (3DEC), incorporating different conditions that will affect the behaviour of the rock mass.

\section{West wall stability of Los Pelambres mine: case study application}

Information supplied by Los Pelambres mine (Figure 2). This mine is located $200 \mathrm{~km}$ north of Santiago and $45 \mathrm{~km}$ east of Salamanca in the Choapa Province. It was discovered in the 1920s by one of Chilean copper's founding fathers, William Braden.

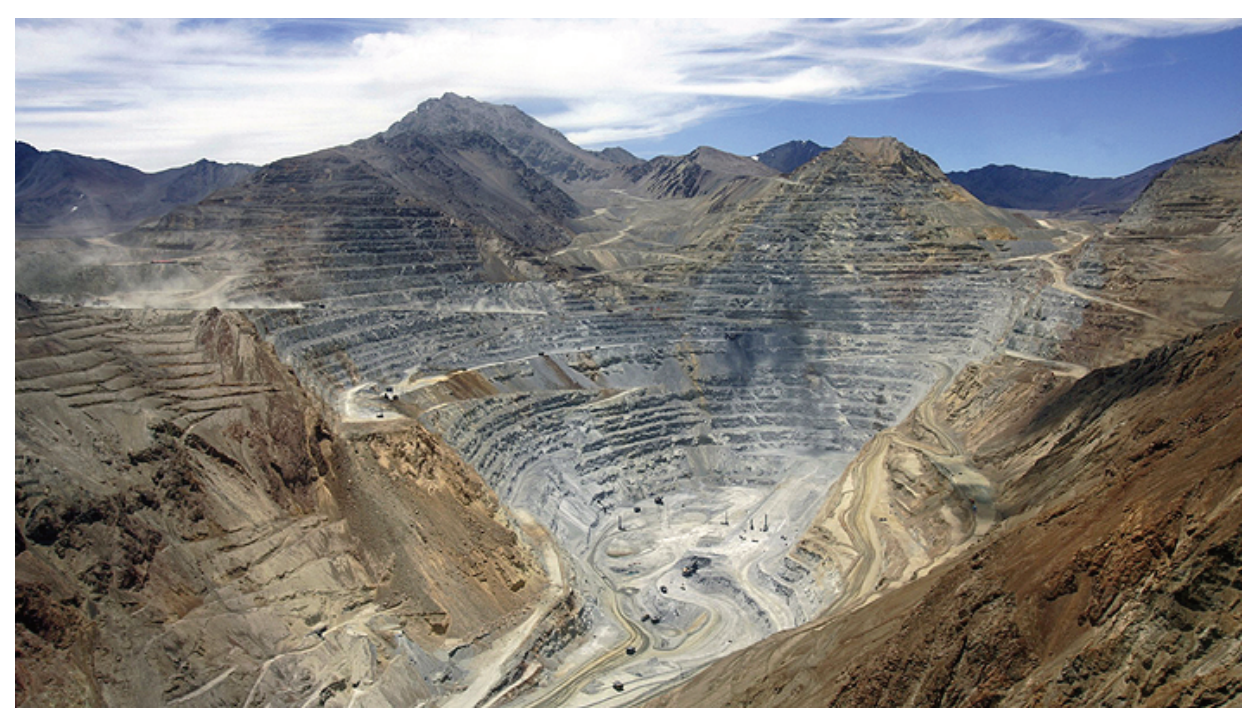

Figure 2 Los Pelambres mine

Antofagasta Holdings started the project in the 1990s and since then, the mine has become one of the biggest copper mines in the world. The Los Pelambres mine is estimated to contain 1.2 billion tonnes of proven and probable ore reserves grading $0.06 \%$ copper, $0.020 \%$ molybdenum, and $0.05 \%$ gold, as of 2017 . The expansion project started early this year, and its first production is anticipated for the second half of 2021.

The analysis presented in this document is part of the stability studies that have been carried out regarding these expansions. We will focus on the west wall identified as the most relevant point in terms of stability analysis in the Los Pelambres project. Figure 3 shows the current project and the expansion considered and 
the section view shows the depth of expansion and the influence extent of DFN (only proposed in 300 meters of thickness in order to reduce the requirement computational calculation model).

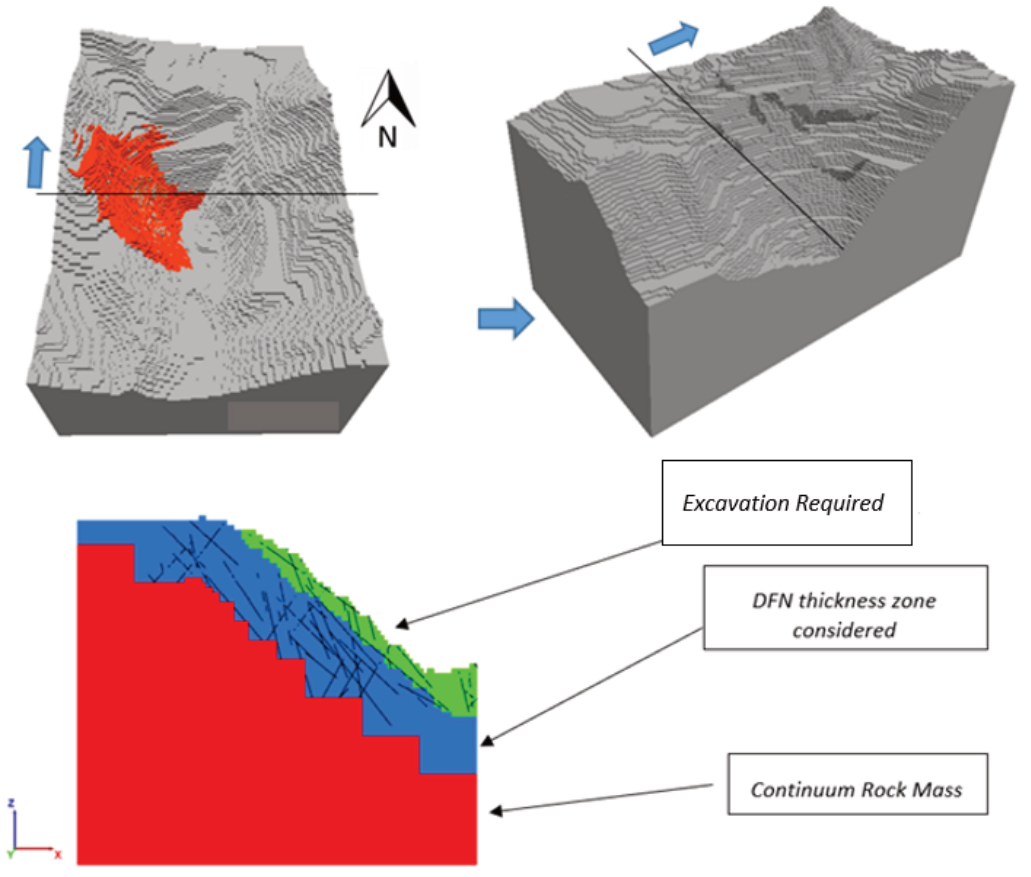

Figure 3 Excavation required and extent of influence of discrete fracture network

\subsection{Geotechnical and structural setting}

The geotechnical environment that exists in the west wall is composed of different geotechnical units (GU) where the best quality can be found in the deepest units. In the surface portion, the geotechnical quality varies from regular (in greater proportion) to poor, especially in specific areas of rock mass like foliation fabric and shear zones. In addition to that, the presence of groundwater in the rock mass has been detected. Meanwhile, according to how the project has progressed, structural geology has been mapped from an early stage, allowing good detail of the discontinuities at inter-ramp and global level.

\subsubsection{Geotechnical units and shear strength criterion}

The GU distribution is shown in Figure 4. The foliated domain is a geotechnical unit that represents areas in the rock mass with foliation fabric or shear zones which are shown in detail in Figure 5.

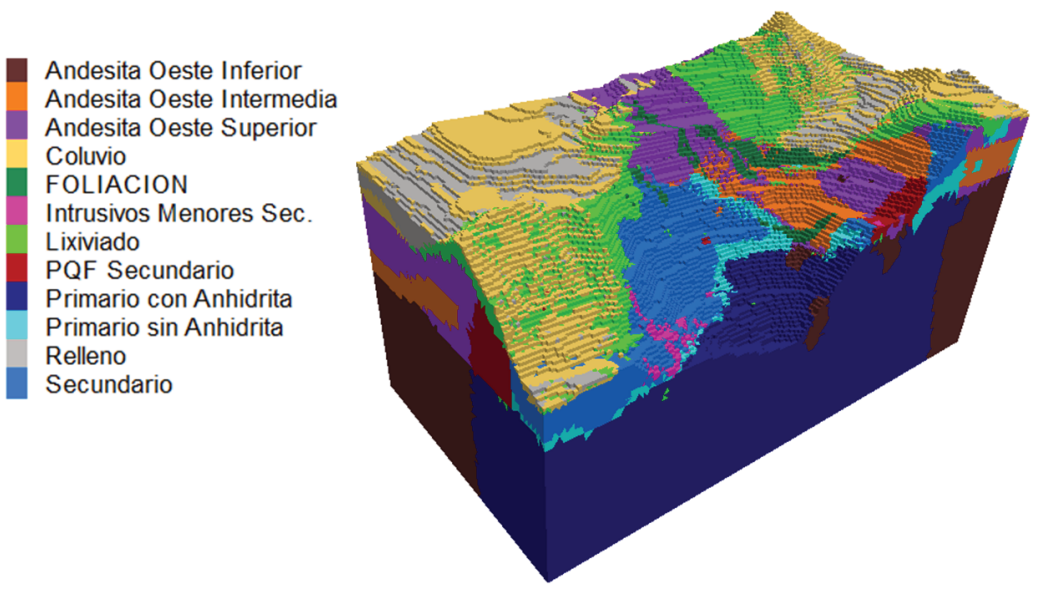

Figure 4 Distribution of geotechnical units 

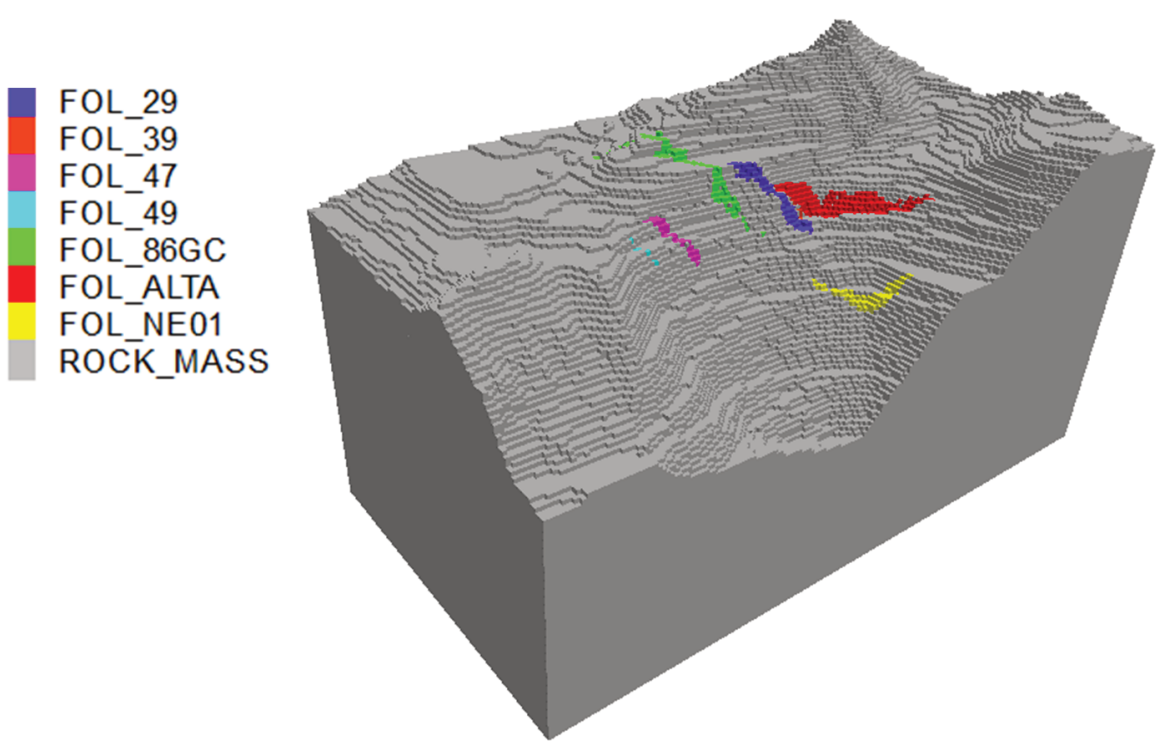

Figure 5 Areas in the rock mass with foliations fabric. The number is only an indicator

As an important fact, the GUs have a geological strength index (GSI) values between $30-50$ except in the 'primario con anhidrita' and 'primario sin anhidrita', which are two types of anhydrite, and the unit 'andesita oeste inferior', which is a type of andesite. These units have GSI greater than 60 points.

For the uniaxial compression strength, the values are between 70-130 MPa. The weakest units are 'lixiviado' with $66 \mathrm{MPa}$ and 'secundario' unit with $76 \mathrm{MPa}$, while 'primario con anhidrita', 'primario sin anhidrita' and 'andesita oeste inferior' their values above $105 \mathrm{MPa}$.

The shear strength criterion used was modified Hoek \& Brown, described by Hoek et al. (2002) except for the 'foliacion' unit where a ubiquitous bilinear model with strength in the direction of weakness (Dip $=61^{\circ}$, Dip-Dir $=127^{\circ}$ ) assigned a $27 \mathrm{kPa}$ cohesion and friction of $23^{\circ}$, in a normal direction to the weakness, a bilinear envelope with a confinement range of 500-1,500 kPa was adjusted (Figure 6). These properties were derived by back-analysis in studies conducted during previous years.

Also, there are two soil types of $\mathrm{GU}$ that were modelled with the Mohr-Coulomb criterion. These correspond to the 'Coluvio' and 'relleno' units, whose properties were calibrated so that the analysis gave priority to the failure of the rock mass before these (Figure 6).
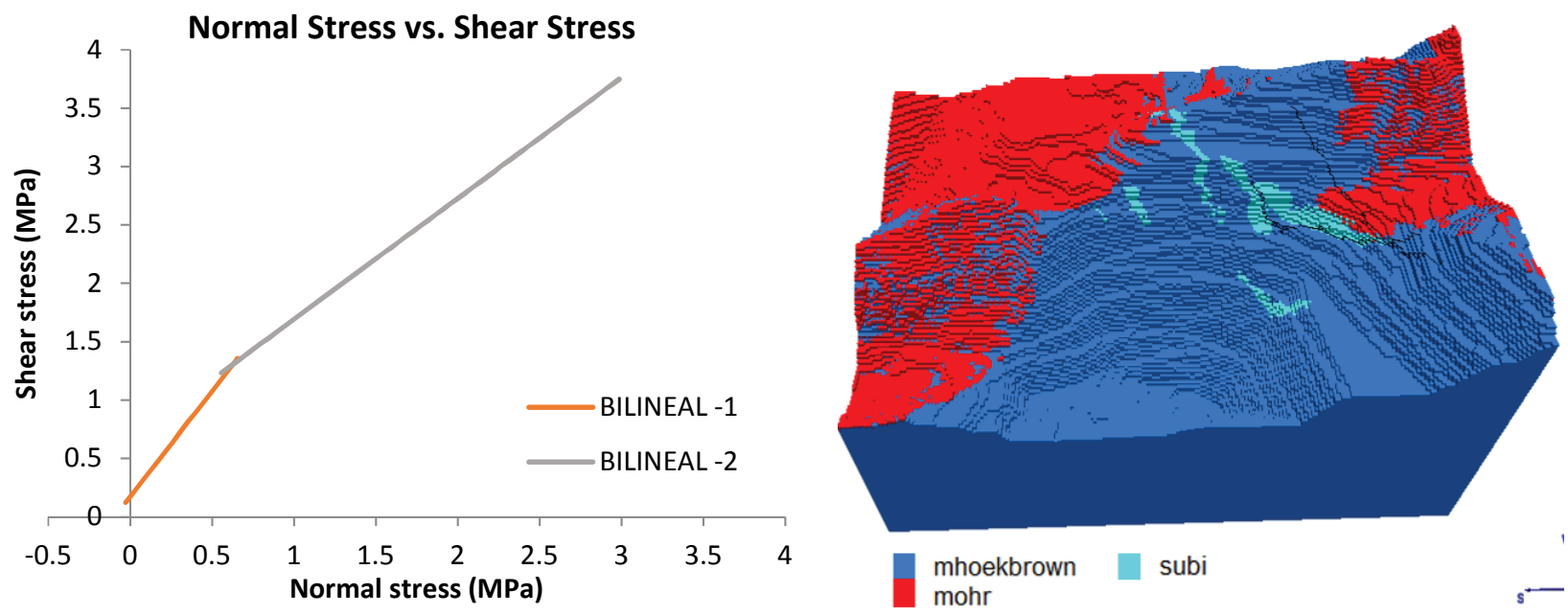

Figure 6 Shear strength models and bilinear envelop 


\subsubsection{Structural data, discrete fracture network development and Joint properties}

Almost 350 persistence structures at inter-ramp were mapped throughout the pit, an overall scale two (2) faults where identified in the west wall with more of $700 \mathrm{~m}$ of persistence each. The structures at interramp scale were represented with disks, allowing to identify the four (4) primary inputs: orientation, intensity, spatial distribution, and size through their stereographic treatment (Weir \& Fowler 2016).

The statistical analysis of the structures starts by separating those that belonged to the west wall, as shown in Figure 7.

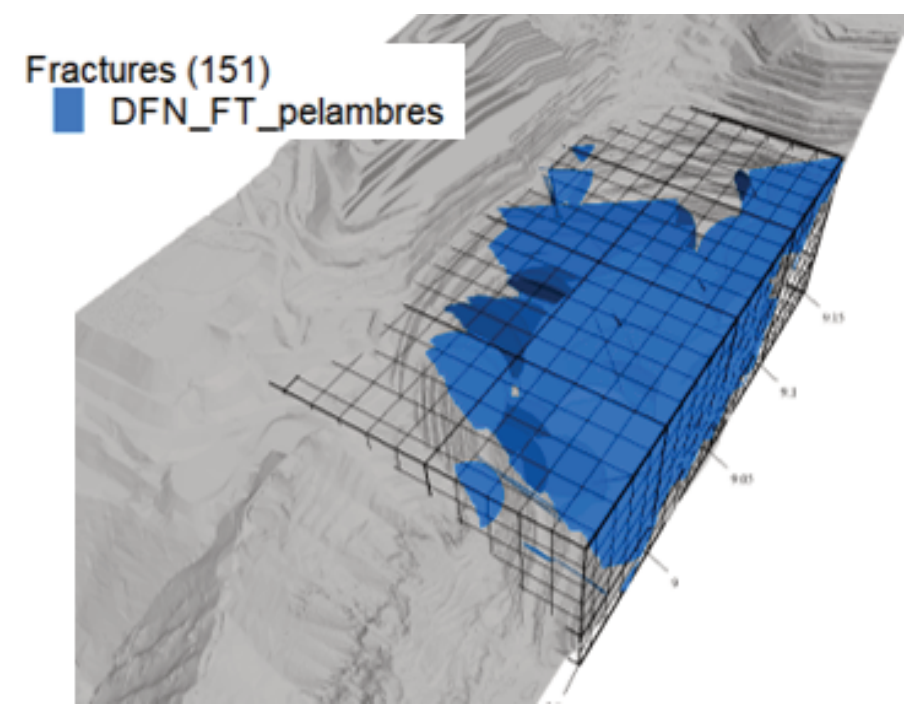

Figure 7 Structures mapped in the west wall

According to Priest (1993), the development of the DFN started with the separation of fractures in sets. Figure 8 shows the set's determinate for this.

To give reliability to the DFN model (Starzec \& Andersson 2002; Dershowitz et al. 2011) and with the use of the correction factor of Terzaghi (1965), sets of alternative fractures were not recognised (Figure 8). Each set was assigned a Fisher (1953) distribution which is equivalent to a normal distribution oriented in a sphere. As for persistence, the diameter of the discs was grouped in a histogram which fit a power curve function with a truncated length up to $700 \mathrm{~m}$. This value is crucial because it prevents the DFN from generating discontinuities of sizes not measured. (Figure 8).
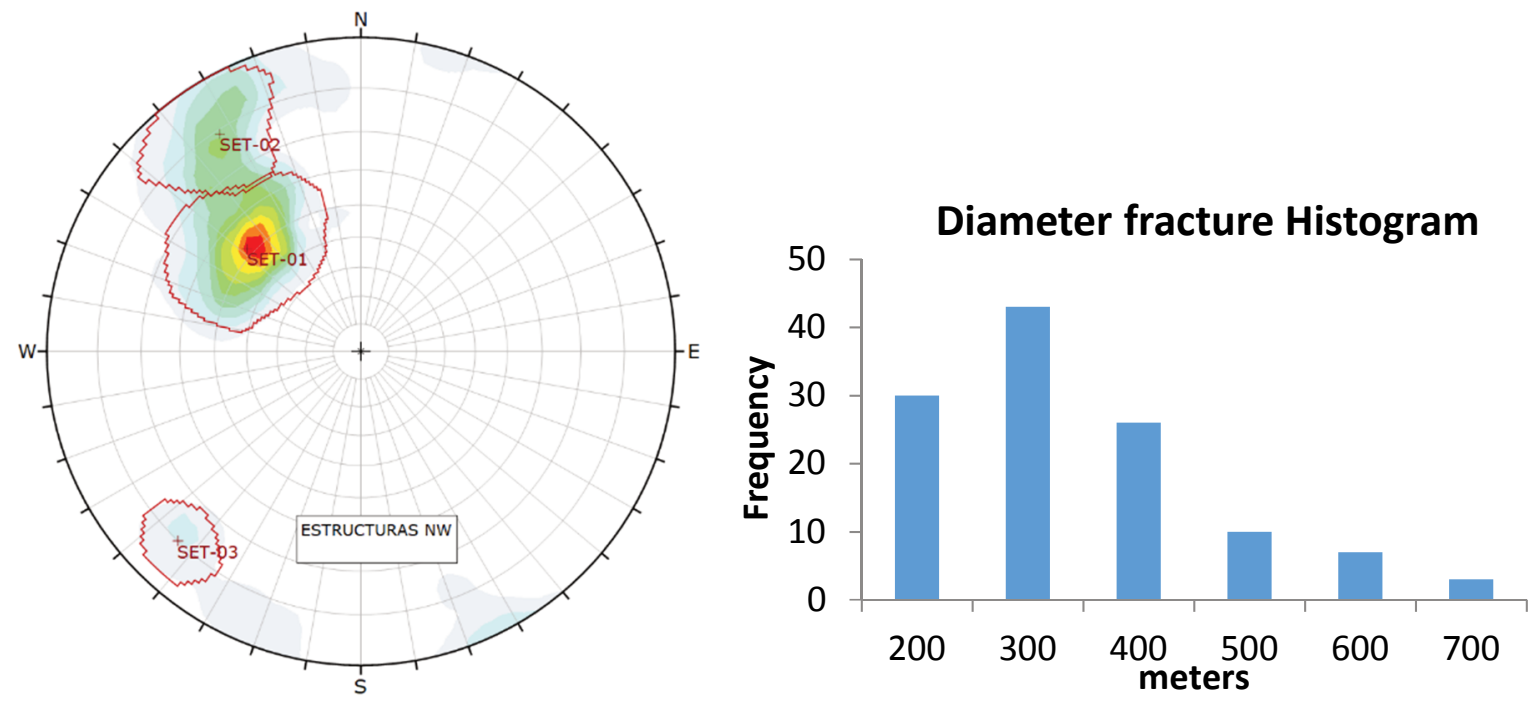

Figure 8 Stereographic projection and fracture persistence histogram in the west wall 
For the intensity and spatial distribution, the $P_{32}$ value was determined. $P_{32}$ is defined as fracture abundance measure (Mauldon \& Dershowitz 2000) which relates the fracture surface area per unit volume of rock $\left(\mathrm{m}^{2} / \mathrm{m}^{3}\right)$.

The determination of $\mathrm{P}_{32}$ was made from the fact that discontinuities were measured in previous stages of the project, permitting its distribution to be wrapped in a limited volume. Evaluating the areas of the discs and the volume that contains them, it is feasible to determine the overall $P_{32}$ value and for each set, as shown in Figure 9 and Table 1.

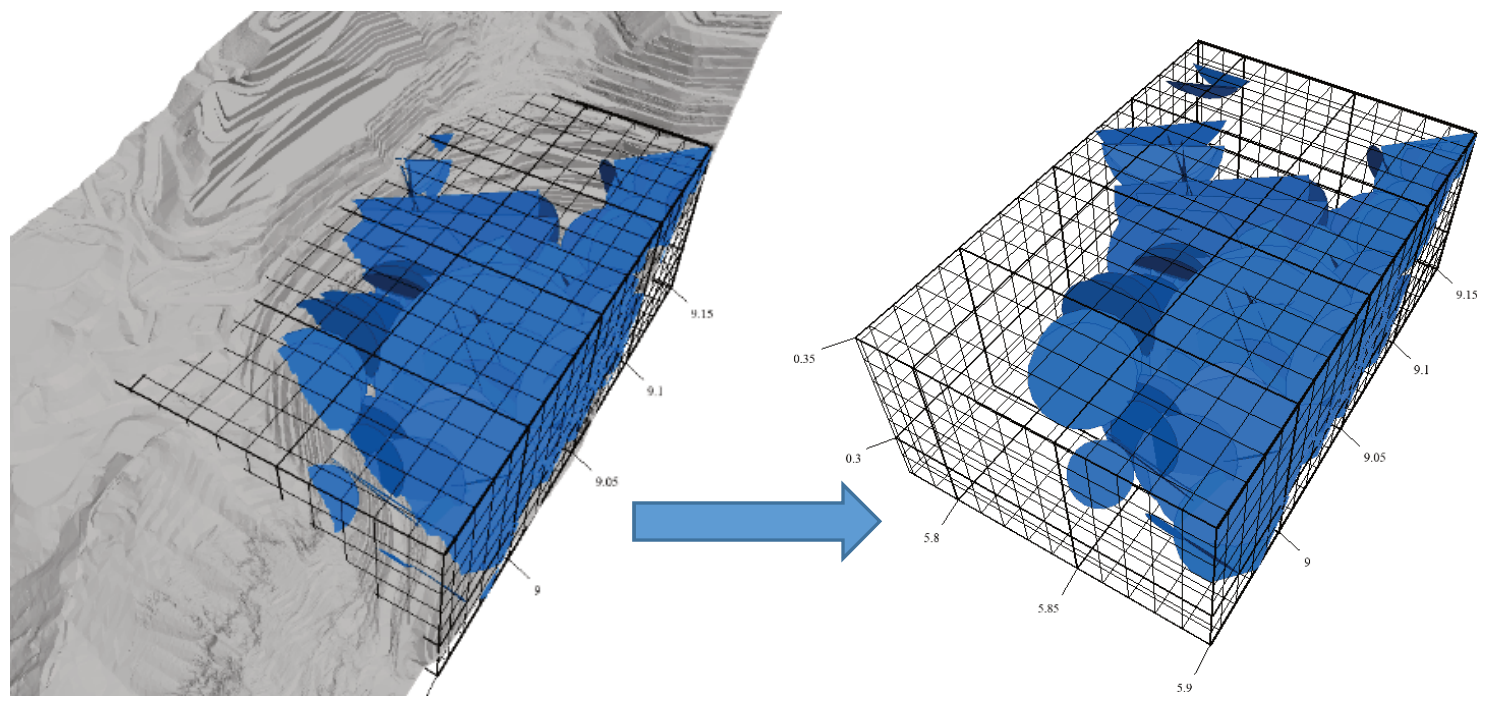

Figure 9 Disks and volume that contains them

Table $1 \quad P_{32}$ Measure

\begin{tabular}{llll}
\hline Total disk area $\left(\mathrm{m}^{2}\right)$ & Volume $\left(\mathbf{m}^{\mathbf{2}}\right)$ & $\mathbf{P}_{\mathbf{3 2}}$ & Details \\
\hline $1.18 \mathrm{E}+05$ & $1.70 \mathrm{E}+09$ & 0.0070 & All sets \\
$9.98 \mathrm{E}+06$ & $1.46 \mathrm{E}+09$ & 0.0065 & Set 1 \\
$1.90 \mathrm{E}+06$ & $1.54 \mathrm{E}+09$ & 0.0012 & Set 2 \\
$5.94 \mathrm{E}+05$ & $1.49 \mathrm{E}+09$ & 0.0004 & Set 3 \\
\hline
\end{tabular}

The resulting DFN is compared with the stereogram generated with the field data. The DFN stereogram result is shown in Figure 10. This comparison allows us to check the representative of DFN model. The summary of DFN parameters can be reviewed in Table 2 .
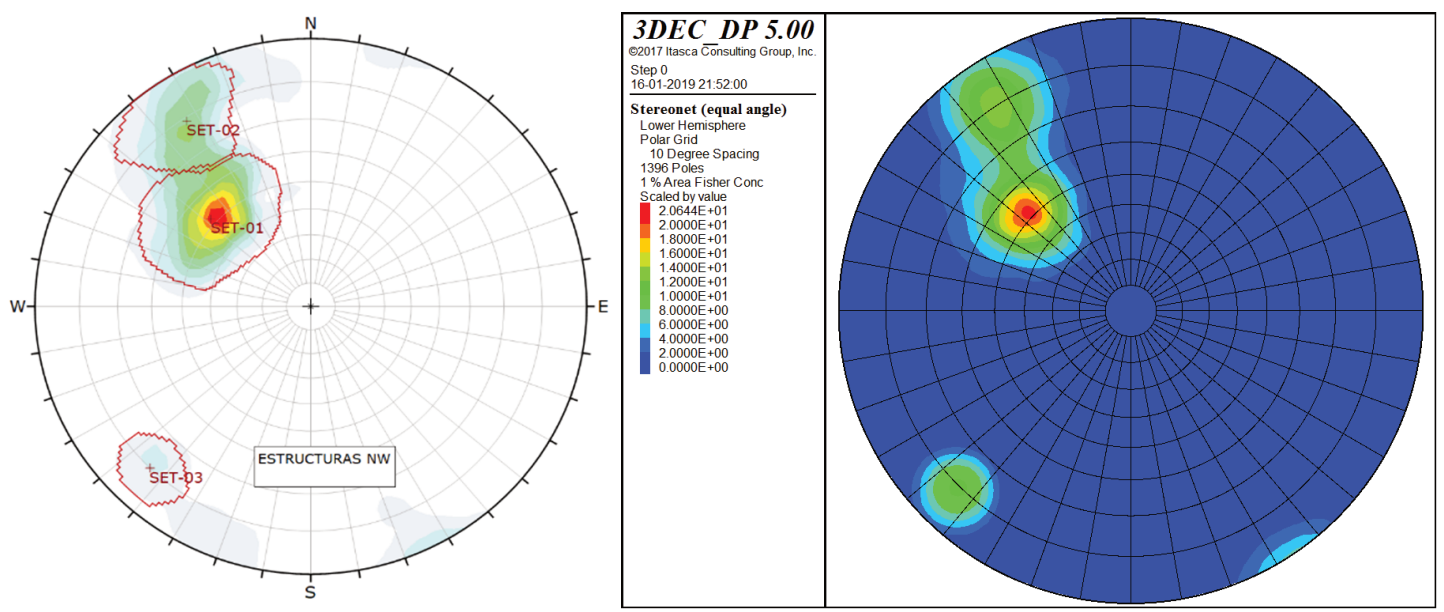

Figure 10 Stereographic field data versus discrete fracture network stereogram 
Table 2 Summary of discrete fracture network data

\begin{tabular}{llllllll}
\hline SET & $\begin{array}{l}\text { Dip } \\
(\mathbf{})\end{array}$ & $\begin{array}{l}\text { Dip-dir } \\
\mathbf{(}^{\circ}\end{array}$ & K-Fisher & $\begin{array}{l}\text { Persistence } \\
\text { function }\end{array}$ & $\begin{array}{l}\text { Low } \\
\text { persistence }(\mathbf{m})\end{array}$ & $\begin{array}{l}\text { Superior } \\
\text { persistence }(\mathbf{m})\end{array}$ & $\begin{array}{l}\mathbf{P}_{\mathbf{3 2}} \\
\left(\mathbf{m}^{\mathbf{2}} / \mathbf{m}^{\mathbf{3}}\right)\end{array}$ \\
\hline 1 & 54 & 131 & 25.56 & Power Law 3 & 100 & 700 & 0.0065 \\
2 & 74 & 24 & 9.53 & Power Law 3 & 100 & 700 & 0.0012 \\
3 & 76 & 204 & 23.27 & Power Law 3 & 100 & 700 & 0.0004 \\
\hline
\end{tabular}

Regarding the two structures of global scale, these will be placed in the models in a deterministic way, building their shape as a model basic input as shown in Figure 11.

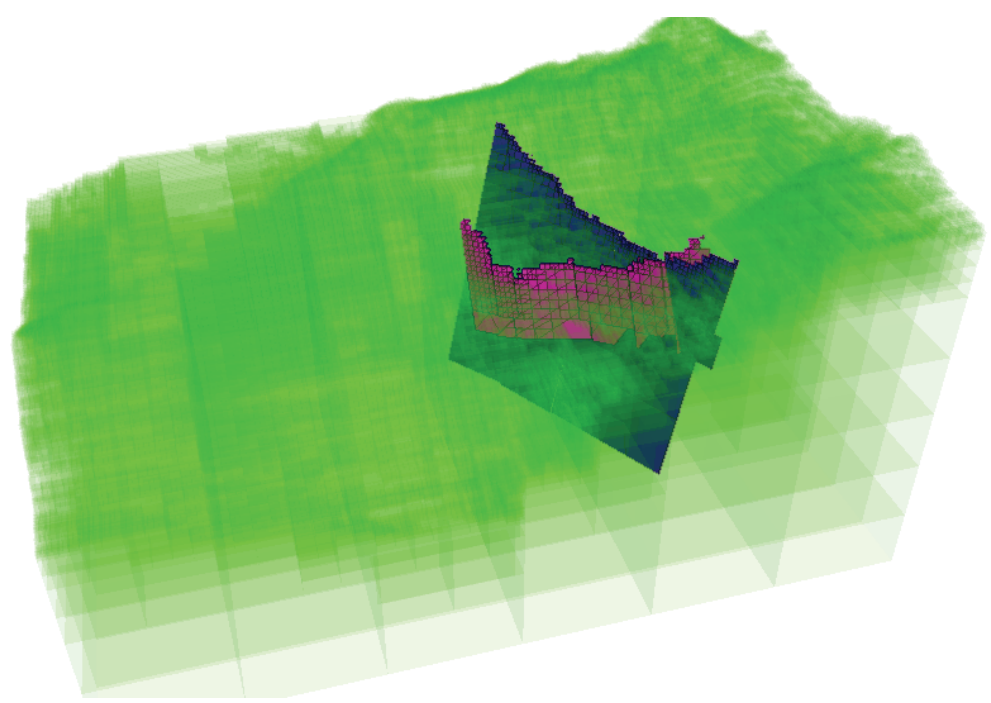

Figure 11 Deterministic joints

An example of DFN fractured model is presented in Figure 12. Finally, the joint properties were described by the Mohr-Coulomb shear criterion, with a cohesion of $27 \mathrm{kPa}$ and friction angle of $23^{\circ}$.
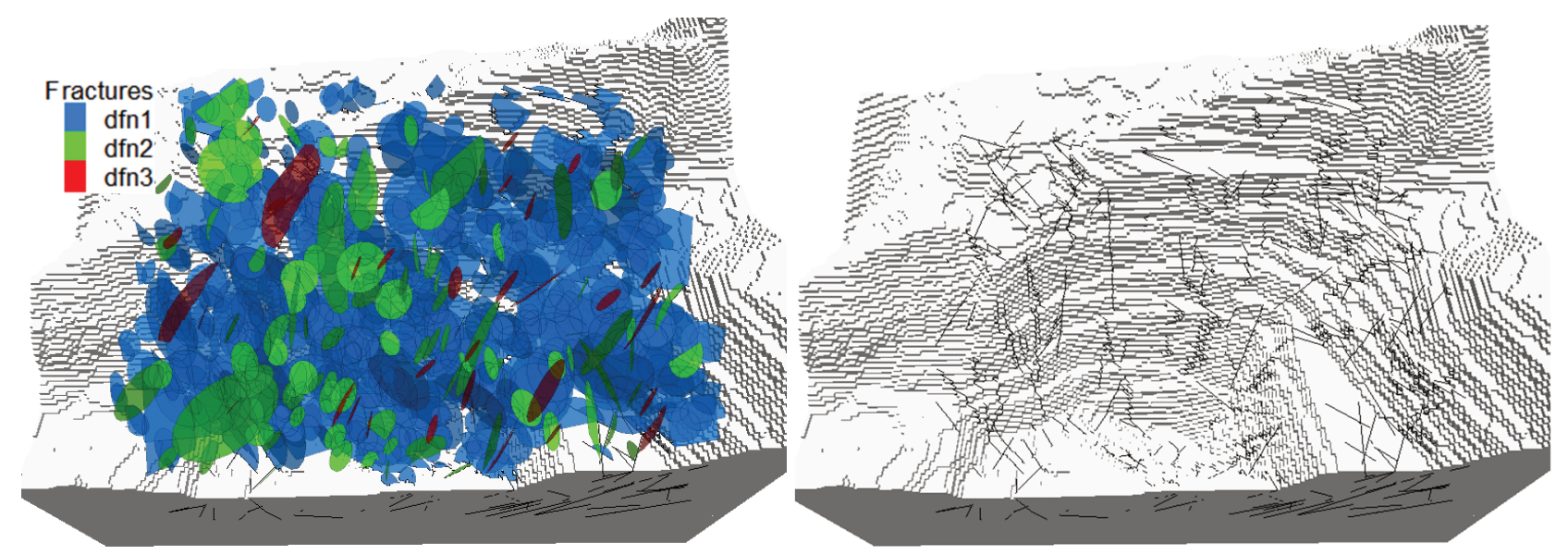

Figure 12 Example of discrete fracture network fractured model

\subsubsection{Groundwater considerations and blast damage}

On the issue of groundwater, recent studies determined a piezometric level of variable elevation. This level at the closest point to the pit is located $20 \mathrm{~m}$ deep. Alongside this level, little piezometric evidence indicates the eventual presence of a shallow level, which affects thickness of $150 \mathrm{~m}$ from the surface (Figure 13). This level is relevant in the analysis because its influence can be determined in the stability while 
hydrogeological studies progress. The pressure of the shallow level has been defined with the following gradient:

$$
P p=\rho g h
$$

where:

$$
\begin{aligned}
& \mathrm{Pp} \quad=\text { pore pressure. } \\
& \mathrm{P} \quad=\text { density of water. } \\
& \mathrm{g} \quad=\text { gravitational acceleration. } \\
& \mathrm{h} \quad=\text { surface level. }
\end{aligned}
$$

\begin{tabular}{|l|}
\hline Pore Pressure \\
\hline $1.7726 \mathrm{E}+07$ \\
$1.7000 \mathrm{E}+07$ \\
$1.6000 \mathrm{E}+07$ \\
$1.5000 \mathrm{E}+07$ \\
$1.4000 \mathrm{E}+07$ \\
$1.3000 \mathrm{E}+07$ \\
$1.2000 \mathrm{E}+07$ \\
$1.1000 \mathrm{E}+07$ \\
$1.0000 \mathrm{E}+07$ \\
$9.0000 \mathrm{E}+06$ \\
$8.0000 \mathrm{E}+06$ \\
$7.0000 \mathrm{E}+06$ \\
$6.0000 \mathrm{E}+06$ \\
$5.0000 \mathrm{E}+06$ \\
$4.0000 \mathrm{E}+06$ \\
$3.0000 \mathrm{E}+06$ \\
$2.0000 \mathrm{E}+06$ \\
$1.0000 \mathrm{E}+06$ \\
$0.0000 \mathrm{E}+00$
\end{tabular}

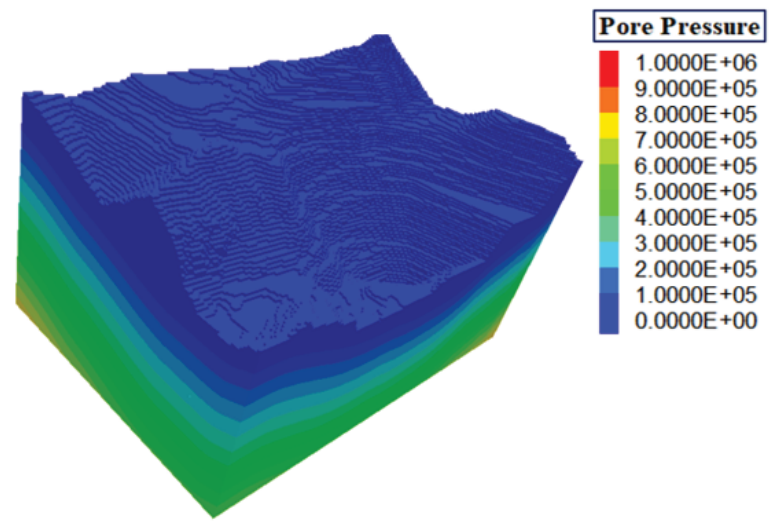

(a)

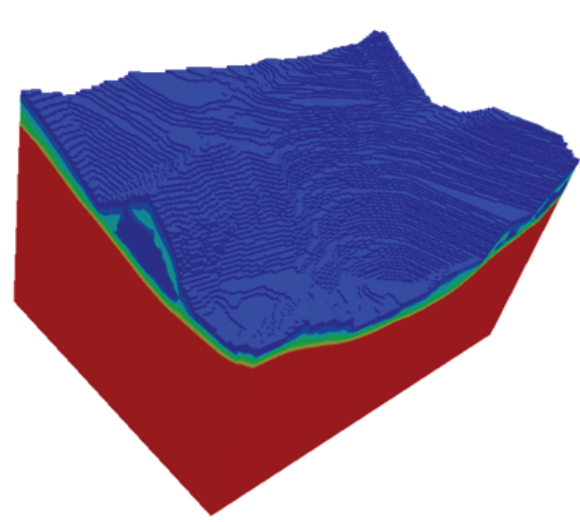

(b)

Figure 13 Groundwater conditions. (a) Deep water level; (b) Shallow level and deep level

Regarding the considerations of blast damage, the recommendations of Hoek (2012) have been followed defining a thickness of $32 \mathrm{~m}$ with a value $\mathrm{D}=0.7$.

\subsection{Stability analysis and modelling outcomes}

Due to the nature generated by the DFN, this type of stability analysis is carried out using a stochastic approach. The stochastic approach is based on generating a probabilistic scenario resulting from a set of input parameters and functions that describe the different distributions of the data. Coates (1981) indicates that probabilistic techniques are direct ways to consider the inherent variety presented by the data. The models built in 3DEC were executed with deformable blocks in a topographic state of stress in the condition and without any previous excavation sequences, as shown in Figure 12.

It is important to indicate that each time a stochastic model is implemented, a different result must be expected so it is necessary to have enough analysis scenarios to understand the distributions obtained in the output data. The results shown in this document concern 36 models where the generation of the DFN was modified by changing the seed value that generates it.

\subsubsection{Stability assessment with stochastic approach}

In the stochastic models generated, the strength reduction method will be used to determine the safety factor and the area that presents this value. Some results are presented in Figure 14. 


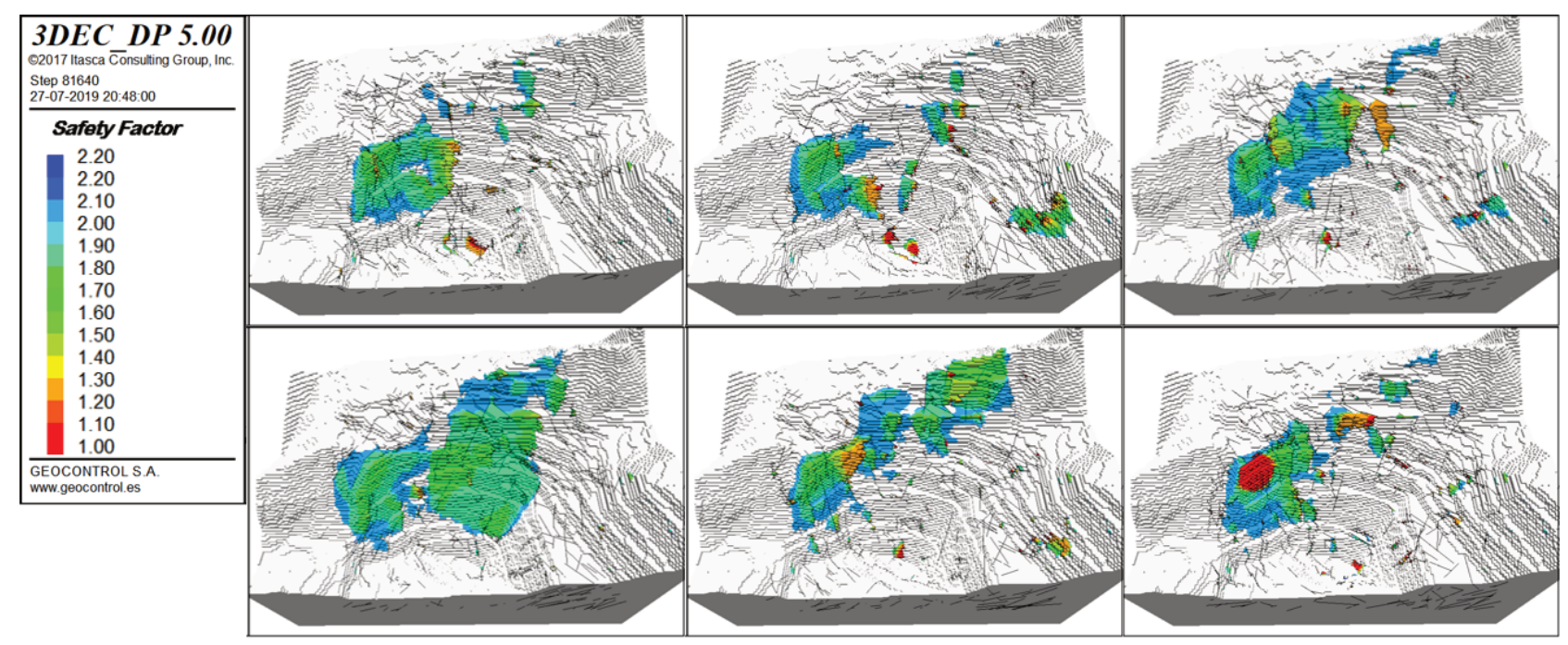

Figure 14 Examples of results of distribution of safety factor

In each simulation trial, the distribution of safety factor depends basically on the DFN generated. In order to analyse the data obtained, the study of the safety factor was limited to the areas that presented SF $<1.0$ and SF $<1.3$, taking into account the detail the volumes produced and their mechanism of failure. The results obtained are presented below.

\subsubsection{Valuation and significance of unstable volumes}

Figure 15 shows the cumulative volume for $\mathrm{SF}<1.0$ and $\mathrm{SF}<1.3$. These results show that the development of instabilities (SF $<1$ ) produces a volume of $0.08 \mathrm{Mm}^{3}$ in $80 \%$ of cases. This value corresponds to the waste volume and its use can be extended to the economic evaluation environment of the design.

On the other hand, the volume of SF $<1.3$ can be used to determine the importance of possible volumes that can develop extraordinary events.

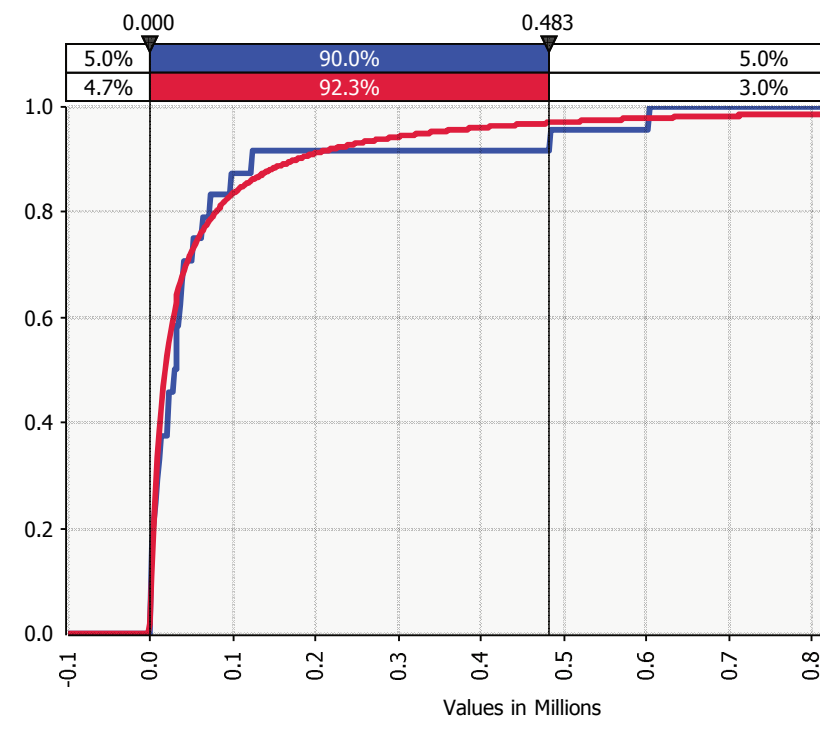

(a)

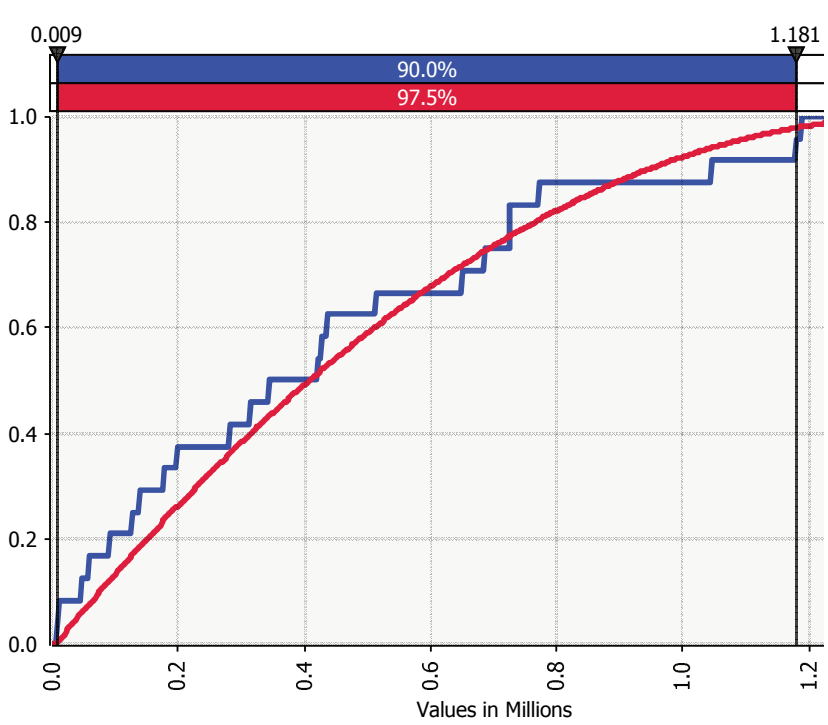

(b)

Figure 15 Cumulative volume for (a) SF $<1.0$; (b) $\mathrm{SF}<1.3$

In the case of instabilities volume, Los Pelambres mine has a follow-up historical measurement of rockfalls in the west wall (Figure 16). The volume reported as the sum of the cases is approximately $0.086 \mathrm{Mm}^{3}$; a value that approximates that defined in the stochastic analyses. 


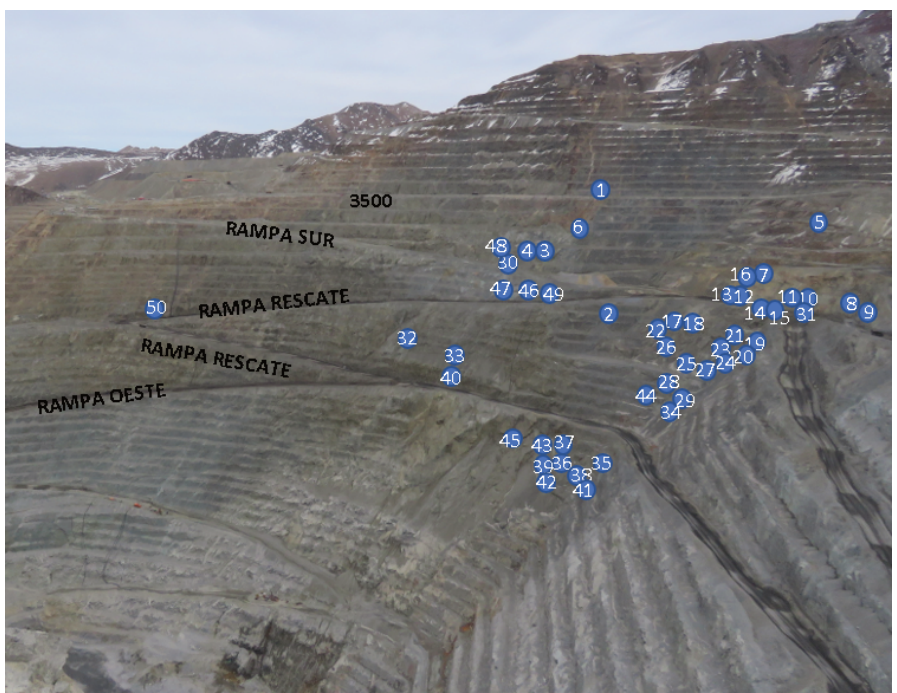

Figure 16 Zones of historical instabilities at the west wall

Given the possibility of the greater volumes, these results only show the need for more accurate cumulative volumes and the importance of stochastic analysis. Recent observations in the field show the need to execute more simulations in order to establish a more adjusted cumulative volume and verify if some calibration is required in terms of shear strength.

\subsubsection{Critical characteristics of failure mechanisms}

In order to identify the most important characteristics involved in failure mechanisms, a detailed description of each zone that previously presented unfavourable safety factors (SF <1.0) was made. Each instability is marked with its own identification according to the failure mechanism presented during the analysis. Each failure was analysed in terms of how the joints participated in the failure mechanism, separated by the number of the intersections and the presence of rock mass (Figure 17).
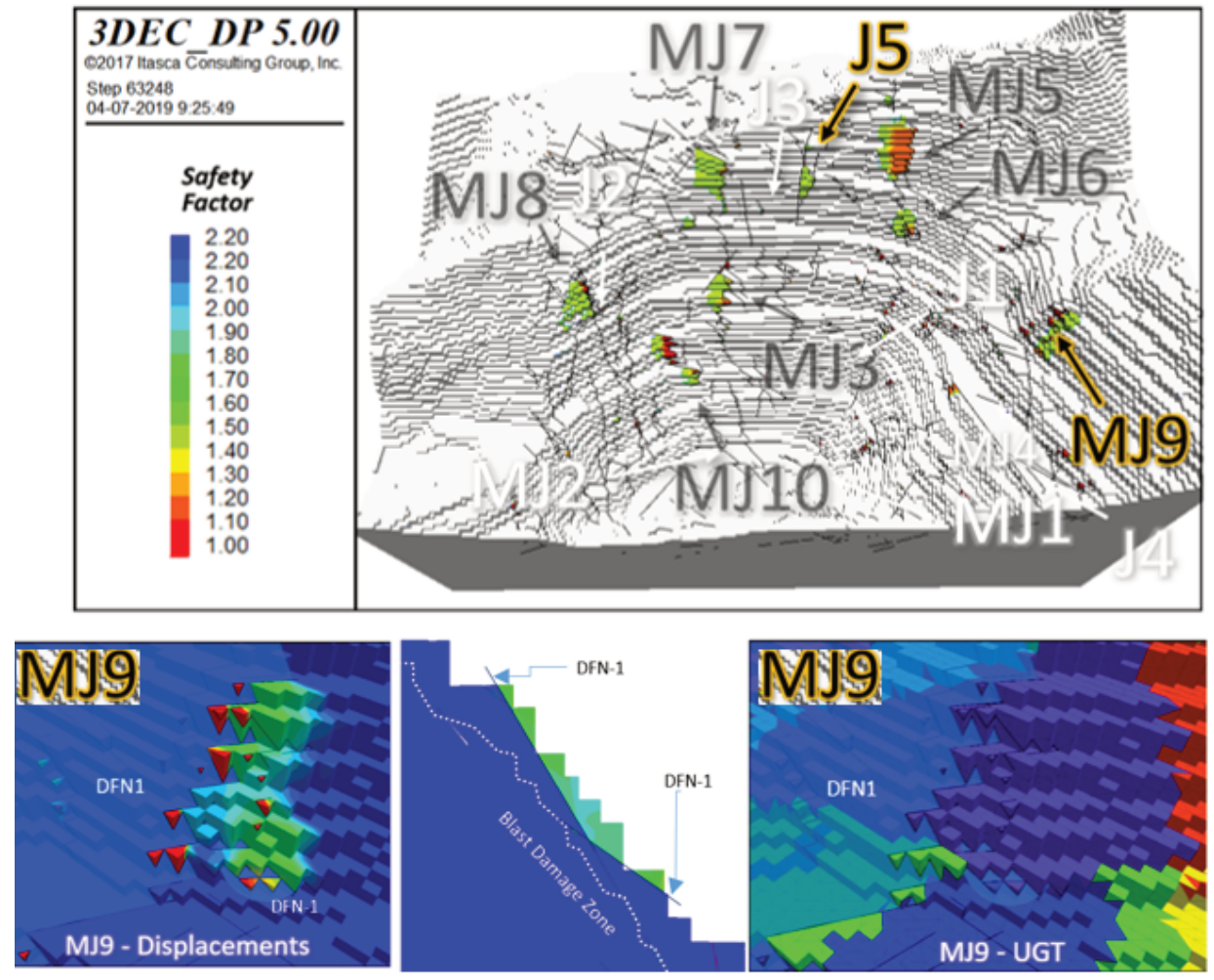

Figure 17 Identification of important characteristics in failure mechanisms 
From the conclusions of the review carried out, the most important characteristics regarding the failure mechanisms of each geotechnical unit and their interaction with the different DFN could be found (circular failure, plane, wedge, toppling, mixed joint-matrix failure, mixed failure of two joints-matrix, etc.).

In addition, the dimension and geometric characteristics (persistence, orientation, family, etc.) of the structures that participate in instabilities can be identified using the number of benches that are affected, thus being able to indicate the importance that each characteristic has in relation to the frequency they present.

The results obtained are summarised in Table 3, it is practical for this article to describe instabilities in detail due to mixed faults (joints-matrix) since structurally controlled mechanisms cannot be prevented with geotechnical field monitoring.

Due to the geotechnical characteristics of the different units in the pit, their response to mixed type instability was conditioned to the non-anhydrite GU.

In addition, the structural persistence must be greater than 3 or 4 benches for the development of instabilities that may concern the process line.

Table 3 Summary of failure mechanism characteristics

\begin{tabular}{|c|c|c|c|c|c|}
\hline $\begin{array}{l}\text { Failure } \\
\text { mechanism }\end{array}$ & $\begin{array}{l}\text { UGT } \\
\text { involve }\end{array}$ & Description & $\begin{array}{l}\text { Benches } \\
\text { affected } \\
\text { (persistence) }\end{array}$ & $\begin{array}{l}\text { Joint set } \\
\text { involve }\end{array}$ & Instability example \\
\hline $\begin{array}{l}\text { Mixed + } 1 \\
\text { joint; non- } \\
\text { outcropping } \\
\text { plane }\end{array}$ & $\begin{array}{l}\text { Non- } \\
\text { anhydrite }\end{array}$ & $\begin{array}{l}\text { Rupture of the } \\
\text { rock matrix has } \\
\text { a discontinuity } \\
\text { below }\end{array}$ & $\begin{array}{l}\text { From } 4 \text { to } 7 \\
\text { benches }\end{array}$ & DFN-1 & \\
\hline $\begin{array}{l}\text { Mixed + } 1 \\
\text { joint; non- } \\
\text { outcropping } \\
\text { side plane }\end{array}$ & $\begin{array}{l}\text { Non- } \\
\text { anhydrite }\end{array}$ & $\begin{array}{l}\text { Rupture of the } \\
\text { rock matrix and } \\
\text { discontinuity } \\
\text { laterally }\end{array}$ & $\begin{array}{l}\text { From } 3 \text { to } 8 \\
\text { benches }\end{array}$ & $\begin{array}{l}\text { DFN-1, } \\
\text { occasionally } \\
\text { DFN-2 }\end{array}$ & \\
\hline $\begin{array}{l}\text { Mixed + } 1 \\
\text { joint; wedge } \\
\text { not } \\
\text { outcropping }\end{array}$ & $\begin{array}{l}\text { Non- } \\
\text { anhydrite }\end{array}$ & $\begin{array}{l}\text { Rupture of the } \\
\text { rock matrix in } \\
\text { combination } \\
\text { with two } \\
\text { discontinuities }\end{array}$ & $\begin{array}{l}\text { From } 3 \text { to } 12 \\
\text { benches }\end{array}$ & $\begin{array}{l}\text { DFN1+DFN1 } \\
\text { DFN1+DFN2 }\end{array}$ & \\
\hline Any & Anhydrite & $\begin{array}{l}\text { Only susceptible } \\
\text { to structurally } \\
\text { controlled } \\
\text { failures }\end{array}$ & $\begin{array}{l}\text { From } 2 \text { to } 4 \\
\text { benches }\end{array}$ & - & \\
\hline
\end{tabular}

\subsubsection{Influence of shallow water level}

The effect of surface water level was evaluated on the premise that the stochastic analysis is consistent in terms of volume with deep water level conditions. In Figure 18, the effect of shallow water level in stability is illustrated. From these differences, it is feasible to consider that the surface water does not represent the observations and response that the excavation has had until today. 


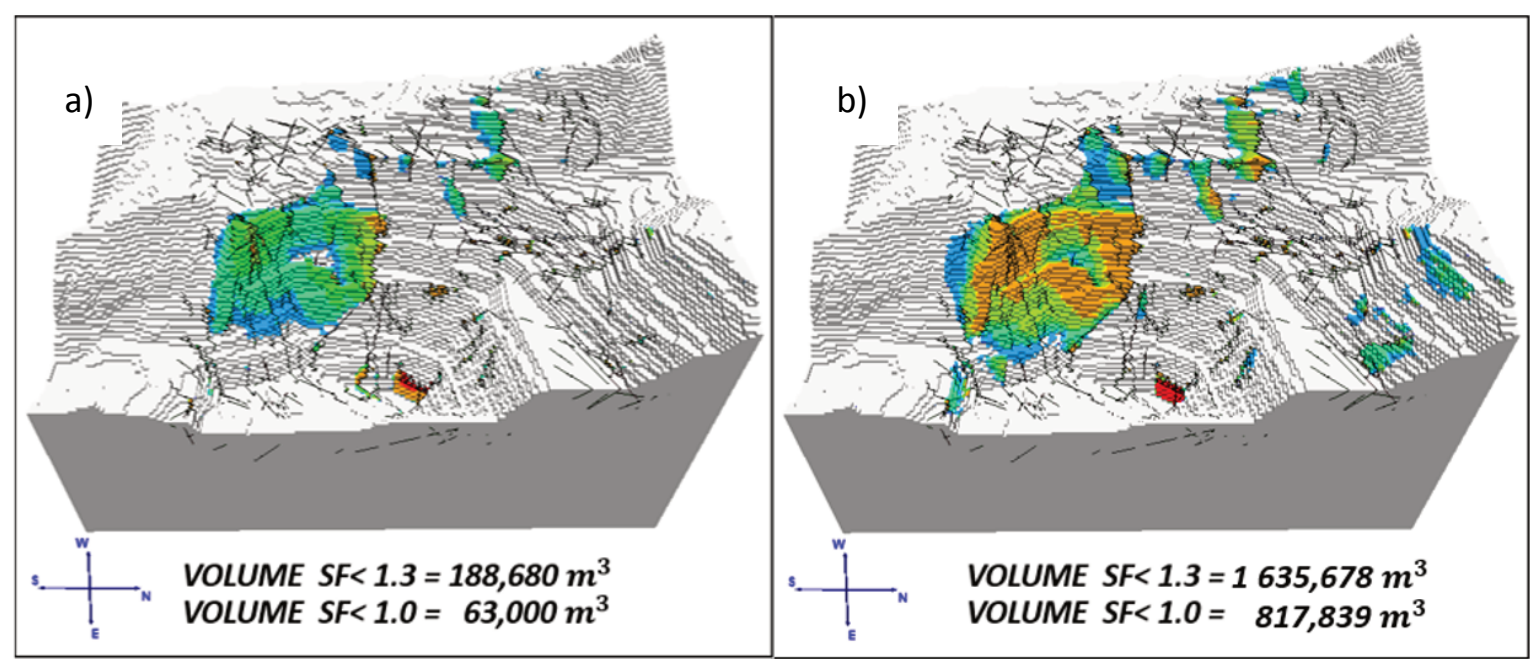

Figure 18 Safety factor considering only (a) deep water level versus (b) deep and shallow water level effect

\section{Conclusion}

The main goal of the current study was to show the application of DFNs in open pit mining from the perspective of volume calculation and determination of types and characteristics of failure mechanisms.

Given the stochastic nature of the DFN, the evidence from this study points towards the idea that each scenario is unique and generates its own results. By analysing the scenarios that were executed, it was possible to assess the volume that could be lost due to inevitable instabilities. The volume that resulted from the analyses was compared to the actual measure of the mine and it showed clear similarities.

As for the failure mechanisms, it was possible to identify the persistence parameter required for the development of instabilities that involved the mixed breakage of the rock mass and different joints, expressed with the number of affected benches, it was feasible to issue geotechnical recognition recommendations in order of anticipating and allowing the monitoring of potential failures in the pit. Finally, it is necessary to generate more stochastic analyses in order to be able to establish if the sample size can support to define more precisely the data obtained in this document taking the basis of the limit central theorem of statistics.

\section{Acknowledgement}

We would like to express our gratitude to Minera Los Pelambres for allowing us to use their information to finalise this research.

\section{References}

Coates, DF 1981, Rock Mechanics Principles, Energy, Mines and Resources Canada, Monograph.

Dershowitz, WS, Lee, G, Geier, J, Foxford, T, La Pointe, P \& Thomas, A 2011, FracMan - Interactive Discrete Feature Data Analysis, Geometric Modelling and Exploration Simulations: User Documentation, version 7.4, Golder Associates, Seattle.

Fisher, R 1953, Dispersion on a sphere, Royal Society London, London, pp. 295-305.

Hoek, E 2012, Blast Damage Factor D, RocNews, https:/www.rocscience.com/documents/pdfs/rocnews/winter2012/BlastDamage-Factor-D-Hoek.pdf

Hoek, E, Carranza, C \& Corkum, B 2002, 'Hoek-Brown failure criterion-2002 edition', Proceedings of the 5th North American Rock Mechanics Symposium and the 17th Tunnelling Association of Canada Conference, University of Toronto, Toronto, pp. 267-273.

Mathis, Jl 2016, 'Structural domain determination - practicality and pitfalls', in PM Dight (ed.), Proceedings of the First Asia Pacific Slope Stability in Mining Conference, Australian Centre for Geomechanics, Perth, pp. 203-212, https://doi.org/ 10.36487/ACG_rep/1604_09_Mathis

Mauldon, M \& Dershowitz, WS 2000 , 'A multi-dimensional system of fracture abundance', Geological Society of America Annual Meeting: Abstracts with Programs, vol. 32, issue 7. 
Priest, SD 1993, Discontinuity Analysis for Rock Engineering, Chapman and Hall, London.

Read, J 2009, 'Slope design methods', in J Read \& P Stacey (eds), Guidelines for Open Pit Slope Design, CSIRO Publishing, Collingwood.

Read, J \& Stacey, P 2009, Guidelines for Open Pit Slope Design, CSIRO Publishing, Collingwood.

Sainsbury, DP, Vakili, A, Lucas, DS \& Hutchinson, BJ 2016, 'Three-dimensional numerical modelling of potential structurally controlled failure mechanisms at the Kanmantoo open pit', in PM Dight (ed.), Proceedings of the First Asia Pacific Slope Stability in Mining Conference, Australian Centre for Geomechanics, Perth, pp. 143-156, https://doi.org/10.36487/ACG_rep/1604_05_Sainsbury

Starzec, P \& Andersson, J 2002, 'Probabilistic predictions regarding key blocks using stochastic discrete fracture networks - examples from a rock cavern in south-east Sweden', Bulletin of Engineering Geology and the Environment, vol. 61, pp. 363-378.

Terzaghi, RD 1965, 'Sources of error in joint surveys', Geotechnique, vol. 15, pp. 287-304.

Tuckey, Z, Stead, D \& Eberhardt, E 2013, 'Combining field methods and numerical modelling to address challenges in characterising discontinuity persistence and intact rock bridges in large open pit slopes', in PM Dight (ed.), Proceedings of the 2013 International Symposium on Slope Stability in Open Pit Mining and Civil Engineering, Australian Centre for Geomechanics, Perth, pp. 189-204, https://doi.org/10.36487/ACG_rep/1308_07_Tuckey

Weir, FM \& Fowler, MJ 2016, 'Discrete fracture network modelling for hard rock slopes', in PM Dight (ed.), Proceedings of the First Asia Pacific Slope Stability in Mining Conference, Australian Centre for Geomechanics, Perth, pp. 157-168, https://doi.org/10.36487/ACG_rep/1604_06_Weir 